\title{
A Compact Key-Shaped Antenna Design for Microwave RFID Applications
}

\author{
${ }^{1}$ YassineGmih, ${ }^{2}$ Younes El Hachimi, ${ }^{3}$ El Mostafa Makroum, \\ ${ }^{4}$ AbdelmajidFarchi \\ 1, 2, 3, ${ }^{4}$ University Hassan $1^{\text {st }}$, Faculty of Science and Technology, Settat-Morocco \\ Laboratory of Engineering, Industrial Management and Innovation, Settat-Morocco
}

\begin{abstract}
This paper presents the design and simulation results of a very compact microstrip patch antenna at $2.45 / 5.8 \mathrm{GHz}$ for Radio Frequency Identification. A good size reduction of $76 \%$ compared to a conventional microstrip antenna is achieved. This antenna has a total area of $31 X 24 \mathrm{~mm}^{2}$ and mounted on an FR4 substrate with dielectric permittivity constant 4.4, thickness of $1.6 \mathrm{~mm}$, loss tangent of 0.025 and has a Microstrip feed Line. The antenna has a low return loss of about $-22.35 \mathrm{~dB}$ with VSWR of almost 1.16 and a good gain of 2.63 dBi at $2.45 \mathrm{GHz}$ and it has return loss of $43.26 \mathrm{~dB}$, VSWR of 1.01 and gain of $3.74 \mathrm{dBi}$ at $5.8 \mathrm{GHz}$. The performance of the proposed antenna is analyzed as well as compared with other RFID antennas at ISM band. It is has been studied, numerically analyzed, simulated using the CST and HFSS software.
\end{abstract}

Keywords: Patch Antenna; RFID (Radio Frequency Identification); microstrip feed line; dual-band frequency; slot; stub; compact size.

\section{Introduction}

Radio Frequency Identification (RFID) is based on radio communication for tagging and identifying an object [1]. It consists of two blocks namely, RFID transceivers (readers) and RFID transponders (tags). A RFID tag consists of a small integrated circuit for storing information and an antenna for communication. A basic RFID system is based on wireless communication between a reader and a tag. RFID readers can read information stored in no line-of sight RFID tags in their vicinity and communicate it to central database system through wired or wireless interface [2]. Over the last few years, RFID has drawn a great deal of attention and it is now widely believed that RFID can bring revolutionary changes [3]. Indeed, applications of RFID systems include supply chain automation, security and access control, cold chain management (temperature logging) and identification of products at check-out points, to name a few. Some of the major retailers have already invested significantly in RFID and mandated their manufacturers to place tags on cases and pallets, which resulted in mass production of inexpensive RFID tags [4].

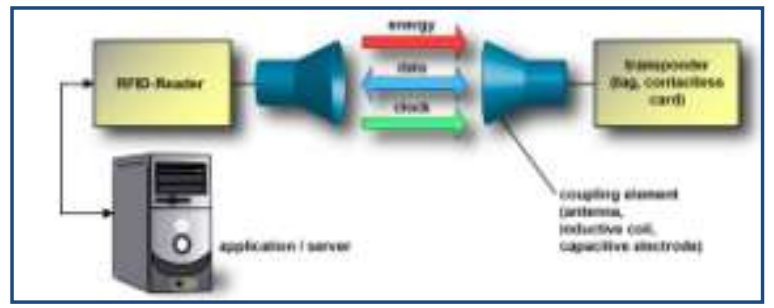

Fig.1 Functioning of an RFID system

Current RFID systems are desinged for applications LF (125 kHz), HF (13.56 MHz), UHF applications ([860-960] MHz) and for microwave applications $(2.45 \mathrm{GHz})$. The technologies associated with these four bands are described and detailed in references [5, 6, 7, and 8].

At present, most of RFID systems operate in the megahertz frequency range. Higher frequencies that utilize free microwave ISM bands such as $2.45 \mathrm{GHz}$ and $5.8 \mathrm{GHz}$ are under active development [9]. In most of the presented microwave RFID system designs, antennas operate at their dominant mode, which is characterized by the lowest frequency of operation. The use of such modes of operation results in large size antennas, which are predominantly responsible for an increased size of an RFID tag. It becomes apparent that in order to miniaturize a microwave ID system, the main assignment is to miniaturize its antenna [10].

Antennas play a very important role in the field of wireless communications. During the recent years, microstrip antennas have attracted an important interest in modern communication systems because of their significant characteristics of small size, light weight, low cost on mass production and thin profile [11]. They are also compatible with wireless communication integrated circuitry due to their simple feed methods, especially

DOI: $10.9790 / 1676-1202035863 \quad$ www.iosrjournals.org $\quad 58 \mid$ Page


microstrip-line and coplanner waveguide feeds. However, their capability to operate at a single frequency, narrow bandwidth and low gain when comparing it with other microwave antennas restrict their practical applications [12].

Because of the low profile and compact size of the planar and printed antennas, there is a strong preference to this type of antennas for applications such as WLAN, UWB, LTE and RFID. Modern mobile and wireless communication systems require compact size, broadband and dual/multi frequency antennas, thus the possibility to apply these antennas for modern communication systems is reinvestigated by applying modifications in their patch geometries [13].

Among these antennas, this work focuses on the rectangular shaped patch antennas which are the subject of much research and development in recent years [14-15].In this work, we suggest to design a new structure of a compact dual-band rectangular patch antenna. This antenna is excited by microstrip line having a power port adapted to $50 \Omega$. A good size reduction of $76 \%$ compared to a conventional microstrip antenna is achieved. The slots and stub inserted at the patch antenna have a direct impact on improving the radiation characteristics as well as the return loss, the bandwidth, the gain and the directivity. The proposed antenna is intended for RFID reader applications in the microwave band.

The rest of this article is organized as follows: Part II presents the design of the proposed microstrip patch antenna. Part III summarizes the simulations results discussion obtained from the antenna and finally part IV concludes the proposed works.

\subsection{Design Equations}

\section{Antenna Design}

Microstrip patch antenna is used at $2.45 \mathrm{GHz}$ and $5.8 \mathrm{GHz}$ as resonance and is fed with a microstrip feed line. The design of the proposed microstrip patch antenna was modeled using the classical equations [16]:

Step 1: Calculation of the Width (W):

$$
W=\frac{c}{2 f r}+\sqrt{\frac{2}{\varepsilon r+1}}
$$

Where, $\mathrm{c}=3 \times 108 \mathrm{~m} / \mathrm{s}, \varepsilon \mathrm{r}=4.4$, fr $=$ Designed Frequency

Step 2: Calculation of Effective dielectric constant (Ereff):

Where, $\mathrm{h}=1.6 \mathrm{~mm}$

$$
\varepsilon e f f=\frac{\varepsilon+1}{2}+\frac{\varepsilon-1}{2}\left[\frac{1}{\sqrt{1+12 \frac{h}{w}}}\right]
$$

Step 3: Calculation of the Effective length (Leff):

$$
\text { Leeff }=\frac{\mathrm{c}}{2 f r \sqrt{\varepsilon r e f f}}
$$

Step 4: Calculation of the length extension $(\Delta \mathrm{L})$ :

$$
\Delta L=0.412 \mathrm{~h} \frac{(\varepsilon r+0.3)\left(\frac{W}{h}+0.264\right)}{(\varepsilon r-0.258)\left(\frac{W}{h}+0.8\right)}
$$

Step 5: Calculation of actual length of patch (L):

$$
L=L \varepsilon e f f-2 \Delta L
$$

\subsection{Model and Geometry of the proposed antenna}

The structure of the proposed antenna has been designed on FR4 substrate $31 \times 24 \mathrm{~mm}^{2}$ (Ls X Ws), with a relative dielectric constant of 4.4 , a thickness of $\mathrm{H}=1.6 \mathrm{~mm}$, a loss tangent $\tan (\delta)=0.025$ and copper foil thickness of $\mathrm{t}=0.035 \mathrm{~mm}$. This antenna is fed by a microstrip line with $50 \Omega$ characteristic impedance. The dimensions of the antenna are optimized and miniaturized by using CST Microwave Studio. The configuration of the proposed antenna is shown in Fig. 2. 


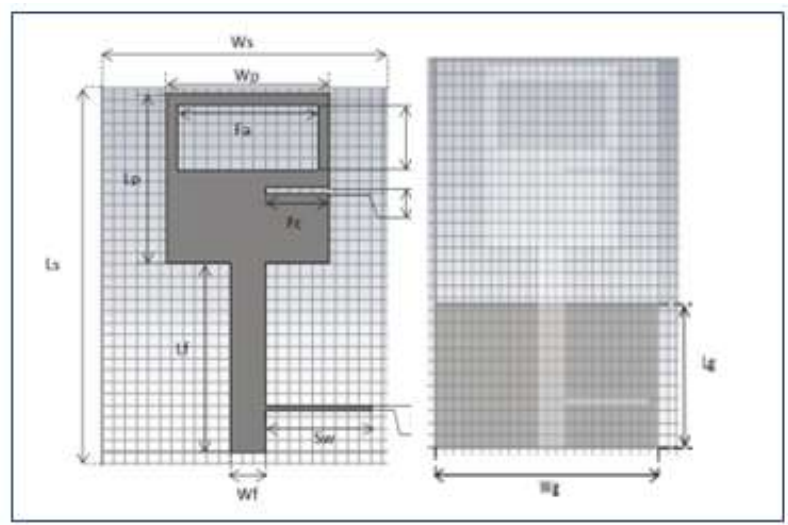

Fig.2Geometry of the proposed antenna

After calculating the dimensions of the basic patch antenna resonating at $2.45 \mathrm{GHz}$. We thought to make our antenna miniaturized and resonate on the two bands of frequencies 2.45 / $5.8 \mathrm{GHz}$.Our antenna has a very simple structure of rectangular shape with 2 slots of different dimensions on the radiating element and a stub on the feeding line. The rectangular slot with dimensions $5 \times 12 \mathrm{~mm}^{2}$ gave rise to dual frequency bands, as well as the small slot of dimensions $5.5 \times 0.5 \mathrm{~mm}^{2}$ was able to widen the bandwidth around the resonant frequency $2.45 \mathrm{GHz}$ which became $400 \mathrm{MHz}$, and Finally, we inserted a stub to the right of the feeding line of dimensions $0.5 \times 9 \mathrm{~mm}^{2}$ in order to improve the adaptation on the two resonance frequencies.

After optimizing the various parameters of our antenna and validating the choice of substrate type and its height, the optimized final dimensions of the antenna by electromagnetic simulation are as follows: patch length $\mathrm{Lp}=14.4 \mathrm{~mm}$, patch width $\mathrm{Wp}=14 \mathrm{~mm}$, feed-line width $\mathrm{Wf}=3 \mathrm{~mm}$, feed-line length $\mathrm{Lf}=16.1 \mathrm{~mm}$, length of ground $\mathrm{Lg}=11.5 \mathrm{~mm}$ and width of ground $\mathrm{Wg}=24 \mathrm{~mm}$. Total volume of the proposed antenna is $31 \times 24 \times 1.6$ $\mathrm{mm}^{3}$.

Table 1 shows the dimensions of the proposed antenna. The global dimensions of the Patch, feed line, ground and substrate have been reduced to miniaturize the final structure.

Table 1: Dimensions of the Proposed Antenna

\begin{tabular}{|l|l|l|l|}
\hline Parameter & Value (mm) & Parameter & Value $(\mathbf{m m})$ \\
\hline $\mathrm{L}_{\mathrm{s}}$ & 31 & $\mathrm{Wf}$ & 3 \\
\hline $\mathrm{W}_{\mathrm{s}}$ & 24 & $\mathrm{Fa}$ & 12 \\
\hline $\mathrm{L}_{\mathrm{g}}$ & 11.5 & $\mathrm{Fb}$ & 5 \\
\hline $\mathrm{W}_{\mathrm{g}}$ & 24 & $\mathrm{Fc}$ & 5.5 \\
\hline $\mathrm{L}_{\mathrm{p}}$ & 14.4 & $\mathrm{Fd}$ & 0.5 \\
\hline $\mathrm{W}_{\mathrm{p}}$ & 14 & $\mathrm{SW}$ & 9 \\
\hline $\mathrm{Lf}$ & 16.1 & $\mathrm{Sl}$ & 0.5 \\
\hline
\end{tabular}

\section{Simulations Results And Discussions}

To make the design, study and analysis of the various parameters of our antenna (adaptation and radiation pattern), we used the electromagnetic simulator CST Microwave Studio whose numerical analysis is based on the finite integration technique [17].In the same time to do a comparison with another EM solver, we have conducted a second study by using HFSS software " high-frequency structural simulator " whose numerical analysis is based on the finite element method [18]. Fig.3 shows a comparison between the simulated return loss versus frequency for the proposed antenna using CST and HFSS.

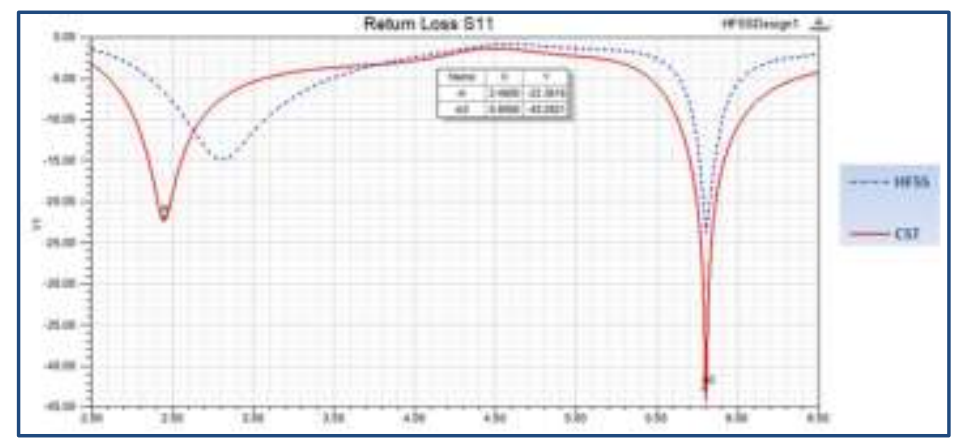

Fig.3Comparison of simulated return loss S11 for the proposed dual-band antenna using CST and HFSS 
The simulation results obtained by the simulators HFSS and CST are nearly similar. The slight difference recorded in terms of reflection coefficients and resonant frequencies are due to the simulation step and the mesh used for each simulator during the simulation. The reflection coefficient curve shows that the designed antenna resonates at $2.45 \mathrm{GHz}$ with a bandwidth of $420 \mathrm{MHz}(2.25-2.67 \mathrm{GHz})$ and at $5.8 \mathrm{GHz}$ with an impedance bandwidth of $400 \mathrm{MHz}(5.61-6.01 \mathrm{GHz})$. The maximum return loss of $-22.35 \mathrm{~dB}$ and $-43.26 \mathrm{~dB}$ is obtained at the resonant frequencies of $2.45 \mathrm{GHz}$ and $5.8 \mathrm{GHz}$ respectively. Moreover, we note a good agreement between both simulation results.

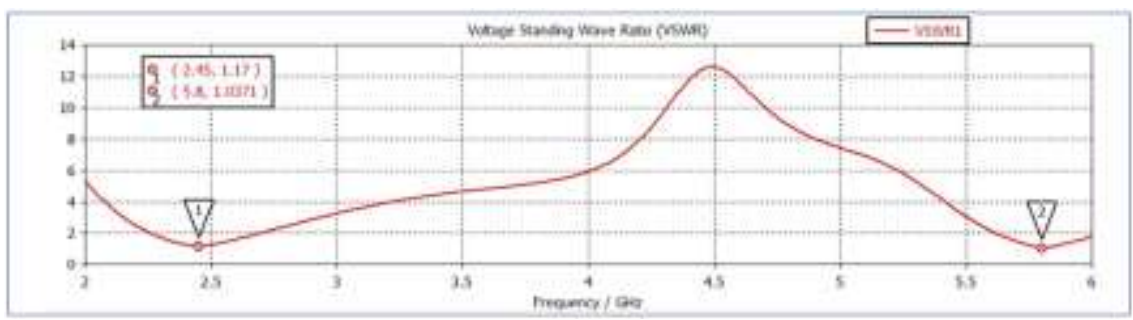

Fig.4 VSWR of the proposed antenna

The Voltage Standing Wave Ratio (VSWR) plot obtained from the simulation of designed antenna is shown in Fig.4. The antenna has a VSWR of $1.16<2$ at $2.45 \mathrm{GHz}$ which is very near to the desired value of unity and at $5.8 \mathrm{GHz}$ resonant frequency, the VSWR is about $1.01<2$.Figure $5 \& 6$ shows the far-field view for directivity at $2.45 \mathrm{GHz}$ and $5.8 \mathrm{GHz}$ respectively. The directivity is $2.63 \mathrm{dBi}$ at $2.45 \mathrm{GHz}$ and $3.74 \mathrm{dBi}$ at 5.8 $\mathrm{GHz}$.

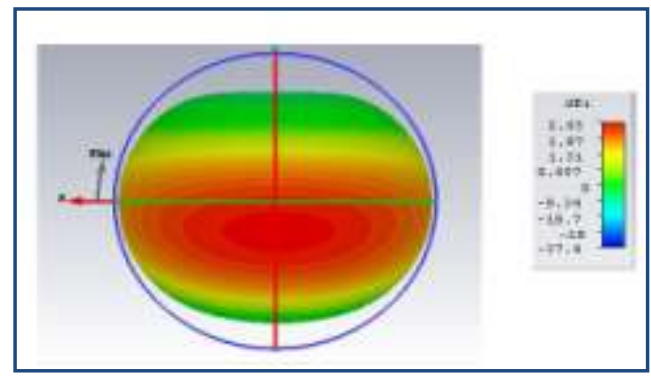

Fig.5Far-field view for directivity at $2.45 \mathrm{GHz}$

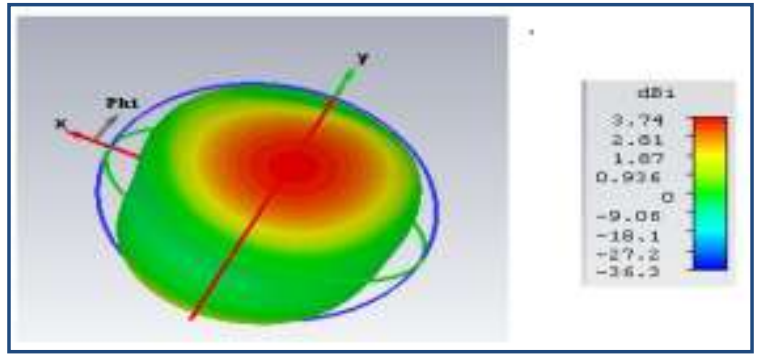

Fig.6 Far-field view for directivity at $5.8 \mathrm{GHz}$

The far field radiation patterns of the final structure in the E-plane $\left(\varphi=90^{\circ}\right)$ and the H-plane $\left(\varphi=0^{\circ}\right)$ for the resonant frequencies $2.4 \mathrm{GHz}$ and $5.8 \mathrm{GHz}$ respectively are represented in figures 7 and 8 .

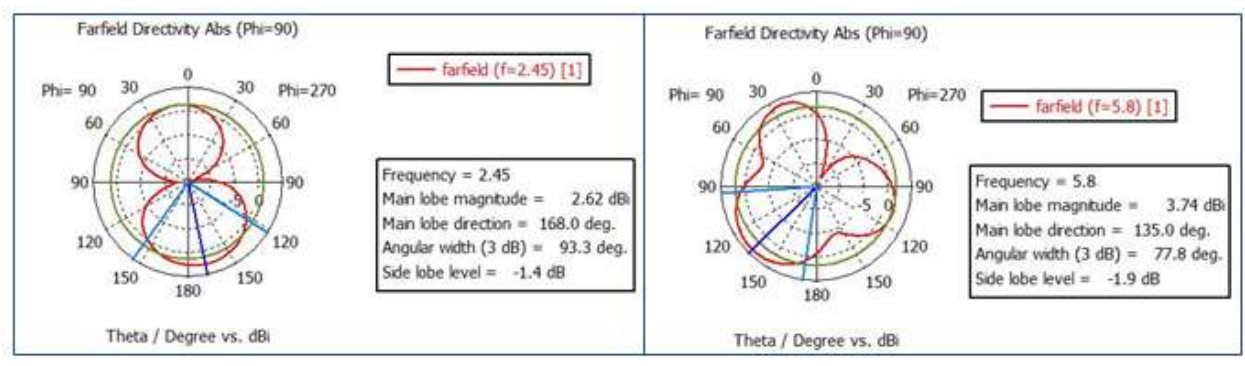

(a)

(b)

Fig.7 Radiation pattern of the antenna in E-plane for (a) $2.45 \mathrm{GHz}$ and (b) $5.8 \mathrm{GHz}$. 


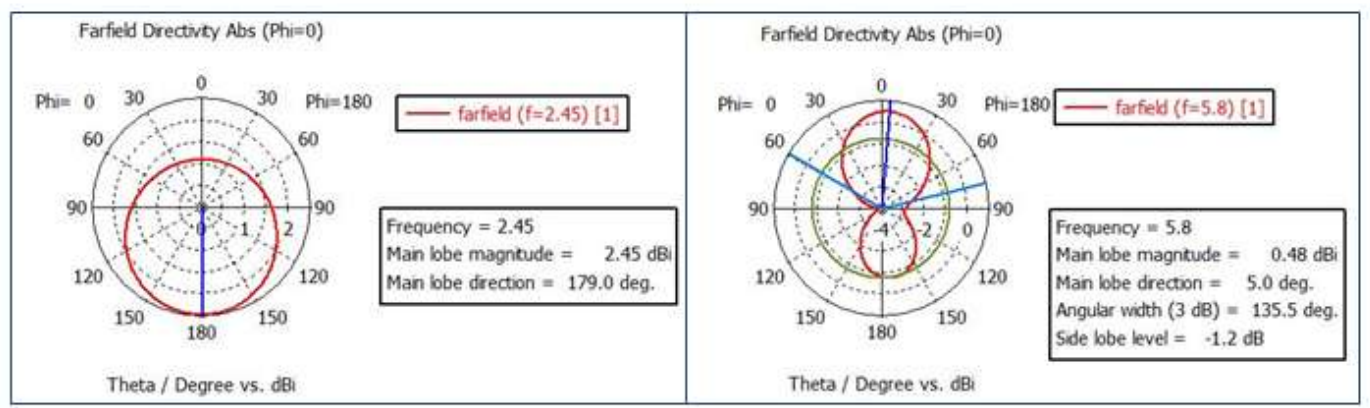

(a)

(b)

Fig.8 Radiation pattern of the antenna in H-plane for (a) $2.45 \mathrm{GHz}$ and (b) $5.8 \mathrm{GHz}$.

It can be observed from the figure 7 that the radiation in the E plane is bidirectional at $2.45 \mathrm{GHz}$ and omnidirectional at $5.8 \mathrm{GHz}$. The main lobes are directed around $0^{\circ}$ and $180^{\circ}$ at both resonant frequencies with magnitude of $2.63 \mathrm{dBi}$ and $3.64 \mathrm{dBi}$ respectively.In the $\mathrm{H}$ plane, the radiation pattern is omnidirectional at 2.45 $\mathrm{GHz}$ and bidirectional at $5.8 \mathrm{GHz}$ with magnitude of $2.45 \mathrm{dBi}$ and $0.48 \mathrm{dBi}$ for the two corresponding resonant frequencies.

The following table summarizes the advantages of the proposed antenna compared to other antennas proposed in the literature such as reflection coefficient, gain, and dimensions. It can be seen that the proposed antenna is significantly smaller, offers an important bandwidth and a good gain compared to its dimensions.

Table 2: Comparison between the proposed antenna and other research papers using the same FR4 substrate

\begin{tabular}{|c|c|c|c|c|c|}
\hline \multirow[t]{2}{*}{ Antennas } & \multirow[t]{2}{*}{ Dimensions $\left(\mathrm{mm}^{3}\right)$} & \multicolumn{2}{|c|}{ Return loss (dB) } & \multicolumn{2}{|c|}{ Gain(dB) } \\
\hline & & $2.45 \mathrm{GHz}$ & $5.8 \mathrm{GHz}$ & $2.45 \mathrm{GHz}$ & $5.8 \mathrm{GHz}$ \\
\hline Ant 1 [19] & $65 \times 52 \times 1.6$ & -33.2 & -22.1 & 2.9 & 1.1 \\
\hline Ant 2 [20] & $50 \times 35 \times 1.6$ & -40.48 & -20.21 & 3.7 & 3.57 \\
\hline Ant 3 [21] & $38 \times 30.6 \times 1.6$ & -18 & -21 & 1.9 & 4.7 \\
\hline Proposed antenna & $31 \times 24 \times 1.6$ & -22.12 & -35.83 & 2.63 & 3.74 \\
\hline
\end{tabular}

\section{Conclusion}

A novel dual-band of rectangular patch antenna has been presented. This validated antenna is suitable for RFID applications which can be used in the released frequency band $2.45 \mathrm{GHz}$ and $5.8 \mathrm{GHz}$, with an impedance bandwidth of $400 \mathrm{MHz}$ at both resonant frequencies. The proposed antenna has been studied, numerically analyzed, simulated using the CST and HFSS software, and fabricated with FR4 substrate with total area $31 \times 24 \times 1.6 \mathrm{~mm}^{3}$. It is compact in size, provides an appropriate gain, consistent radiation patterns, and good impedance matching. It can be handily used in the microwave RFID applications.

\section{References}

[1]. M. Jo, C. G. Lim, and E.W. Zimmers, "RFID tags detection on water content using a back-propagation learning machine," KSII Trans. On Internet and Information Systems, vol. 1, no. 1, pp. 19-32, 2007.

[2]. B. Carbunar, M. K. Ramanathan, M. Koyuturk, C. Hoffmann, and A. Grama, "Redundant-Reader Elimination in RFID Systems," in Proc. 2nd Annu. IEEE Communications and Networks (SECON), 2005, pp. 176-184.

[3]. Y. Bendavid, S. F. Wamba, and L. A. Lefebre, "Proof of concept of and RFID-enabled supply chain in a b2b e-commerce environment," in Proc. 8th Intl. Conf. on Electronic Commerce (ICEC06), 2006, pp. 564-568.

[4]. S. E. Sarma, "Towards the five-cent tag," Technical Report MIT-AUTOAID WH-006, MIT Auto ID Center, 2001.

[5]. K. Finkenzeller, 'RFID Handbook', Second Edition, John Wiley \& Sons, Ltd, 2003.

[6]. D.Bechevet, "Contribution au développement de tags RFID, en UHF et microondes sur matériaux plastiques," thèse doctorat de l'INPG, décembre 2005.

[7]. S.Tedjini, T.P. Vuong, V. Beroulle and P. Marcel, "Radiofrequency identification system from antenna characterization to système validation," Invited paper, Asia-Pacific Microwave Conference, 15-18 december 2004, New Dehli, India.

[8]. G. Backhouse, "RFID: Frequency, standards, adoption and innovation,"JISC Technology and Standars Watch. Available: http://www.jisc.ac.uk/media/documents/techwatch/tsw0602.pdf Accessed: 07 Jan. 2010.

[9]. S.K. Padhi, N.C. Karmakar, C.L. Law and S. Aditya, 2003. A Dual Polarized Aperture Coupled Circular Patch Antenna Using a CShaped Coupling Slot, IEEE Trans. Antennas and Propagation, 51:3295-3298.

[10]. S. K. Padhi, G. F. Swiegers and M. E. Bialkowski, 2004, A Miniaturized Slot Ring Antenna for RFID Applications, in Porc. 15th International Conference on Microwaves, Radar and Wireless Communications, Warszawa, Poland, pp. 318-321.

[11]. Balanis C. A, "Microstrip Antennas", Antenna Theory, Analysis and Design, Third Edition, John Wiley \& Sons, pp-811-876, 2010.

[12]. S. A. Schelkunoff, H.T.Friss, Antennas: Theory and Practice, New York: John Willy \& Sons, 1952.

[13]. R.A.R Ibrahim, M.C.E. Yagoub, R.W.Y. Habash, "Microstrip Patch Antenna for RFID Applications", pp. 940-943, 3-6 May 2009.

[14]. I. Surjati, K. Yuli and A. Astasari, Microstrip Patch Antenna Fed by Inset Microstrip Line for Radio Frequency Identification (RFID), Asia-Pacific International Symposium onElectromagnetic Compatibility, Beijing, China, pp. 1351-1353, 12-16 April 2010. 
[15]. A. El Alami, S.D. Bennani, M. El Bekkali and A.Benbassou, Modélisation d'une Nouvelle Structure d'Antenne Patch Microruban pour une Application RFID, 1er Workshop International sur les Nouvelles Technologies sans Fil et Systèmes Répartis (WITS), Ecole Nationale des Sciences Appliquées, Fès, Maroc, 9-10 Avril 2014.

[16]. Okoshi, T., and T. Miyushi, ,,, The Planar Circuit An Approach to Microwave Integrated Circuitry, ${ }^{\text {,eee }}$ IEEE Trans. Microwave Theory Tech., Vol. 20, April 1972,pp. 245-252.

[17]. CST Studio Suite version 2015:http://www.cst.com

[18]. http://www.ansys.com/Products/Electronics/ANSYS+ HFSS

[19]. B. Parida, A. Kumar and J. Sahay, "Design of Reconfigurable Microstrip Patch Antenna for WLAN Application", International Journal of Modern Trends in Engineering and Research (IJMTER), vol. 1, issue 06, Dec 2014.

[20]. Panda, JyotiRanjan, and Rakhesh Singh Kshetrimayum. "A printed 2.4 GHz/5.8 GHz dual-band monopole antenna with a protruding stub in the ground plane for WLAN and RFID applications" Progress In Electromagnetics Research 117, pp. 425-434, June 16, 2011

[21]. A. El Hamraoui, El H. Abdelmounim, J. Zbitou, H. Bennis, M. Latrach, "A New Design of a Compact CPW-Fed Dual-Band Printed Antenna for RFID Applications", International Conference on Wireless Networks and Mobile Communications (WINCOM), 20-23 Oct.2015,Marrakech,Morocco. 